\title{
O PRIMEIRO DICIONÁRIO BILINGUE PORTUGUÊS QUE UTILIZA UMA LÍNGUA ESTRANGEIRA MODERNA (Sobre dicionários portugueses antigos: uma inventariação II)
}

No quadro das investigações que estou a realizar sobre a história da lexicografia portuguesa, publiquei já alguns volumes com o título "Dicionário dos dicionários portugueses". No primeiro volume de 1994, foram reunidas todas as entradas (lexemas) com as iniciais $\mathrm{ABA}-\mathrm{ABC}$, contidas em mais de 60 dicionários e outras obras de carácter lexicográfico, publicados ao longo de 3 séculos (1554-1858). Deve ser actualmente a lista mais completa deste tipo. As entradas vão acompanhadas do texto completo com o qual os nossos autores de então explicaram ou ilustraram as respectivas entradas. Este primeiro volume permite comparar os diferentes dicionários e analisar como os mais recentes retomaram o que está escrito nos mais antigos, ou como - em casos mais raros— não imitaram senão criaram de novo as suas entradas.

De acordo. com os resultados da análise pormenorizada destes factos, publicados em parte na $R L i R$ 58/1994 e em parte no prefácio do segundo volume (Iniciais $A B D-A B U$ ), reduzimos o conteúdo do segundo volume: contém só 36 dicionários porque muitos dos dicionários registados no primeiro volume não mudaram o texto do seu modelo anterior. Não valia a pena repetir várias vezes a mesma microestructura.

Um projecto de investigação de tal envergadura não pode fazer-se sem a ajuda de meios electrónicos, e a nossa ideia de tornar o material accessível em forma electrónica continua, se bem que a aceitação ainda não seja muito grande. Em contraposição à forma tradicional de publicar livros impressos, este processo permitiria ao utente, por exemplo, fazer pesquisas com este corpus, ou fazer imprimir determinado dicionário antigo, que, hoje, nem mesmo nos alfarrabistas se encontra. No final do ano 1995 apareceu o quinto volume (iniciais AGA-AJU). Para 1996 estão previstos dois volumes com AL, e, para poder avaliar se os lexicógrafos de então mudaram a sua técnica entre o princípio e o fim da obra, prepara-se o volume com a inicial $\mathrm{U}$.

Na fase preparatória deste projecto, decidi incluir só três tipos de dicionários: $1^{\circ}$ monolingues, $2^{\circ}$ bi- ou trilingues com o português como primeira língua, e $3^{\circ}$ dicionários poliglotas antigos. Os dicionários que não estão ordenados segundo o lexema português foram excluídos. Quando tentei reunir as informações bibliográficas constatei que muitas das indicações eram demasiado breves para se poder conhecer realmente os dicionários. Por isso quis eu mesmo ver estas obras. Como resultado deste trabalho bibliográfico publiquei de maneira bastante pormenorizada (com largas listas de palavras e reproduções) a análise de 8 dicionários, entre os quais figura também o famoso "Vocabulario da Lingoa de Japam com 
a declaração em Portugues..." de 1603 (a segunda obra lexicográfica onde aparece a língua japonesa; a primeira é de 1595). Publiquei este estudo com o título "Sobre dicionários portugueses antigos: uma inventariação I" (Messner 1995).

Agora desejo continuar com a mesma temática, e, por isso, pode-se dar ao presente artigo também um subtítulo: "uma inventariação II", com uma restrição: só vai ser apresentado um único dicionário, porque, acho, é uma obra excepcional, e a sua descrição, nunca antes realizada, pode causar alguma sensação. Trata-se do segundo dicionário bilingue português, e do primeiro no qual a segunda língua não é o latim.

Sabe-se que o primeiro dicionário bilingue (português-latim) é da autoria de Jerónimo Cardoso. As frases seguintes são da autoria de Telmo Verdelho $(1994,674)$ : “Os dicionários do humanista Jerónimo Cardoso (c. 1500 - c. 1569...) especialmente o Dictionarium ex Lusitanico in Latinum Sermonem (1562) marcam o início da dicionarização da língua portuguesa. Neste dicionário Cardoso promoveu a primeira alfabetação do "corpus" lexical vernáculo e deu assim origem, com maior ou menor interferência, a todos os subsequentes dicionários do português, repercutindo-se efectivamente na técnica dicionarística, no levantamento das unidades lexicais, na referenciação do seu valor semântico, e na fixação da sua imagem ortográfica".

O segundo dicionário sera o objecto do meu comentário neste artigo: é teoricamente conhecido desde há muito tempo. Lopes 1969:160 escreveu: "Dicionário português-chinês por P.es Ruggieri e Ricci (Existe pelo menos um manuscrito em Roma, redigido entre 1584-1588 ...)".

É estranho que nenhum dos autores que trataram disso, tenha procurado o original (vejamse as citas em Messner 1995).

A figura do jesuíta Mateo Ricci foi várias vezes descrita. Já na obra de Athanasius Kircher, de 1667, mencionam-se as suas obras. Por isso, não é necessário expôr largamente a vida desta personalidade. Nasceu na cidade italiana de Macerata, a 6 de Outubro de 1552, e aderiu à Societas Jesu em 1571. Continuou os seus estudos de teologia em Goa a partir de 1578. Em 1583 viajou para a China, onde morreu, a 11 de Maio de 1610 . Num livro mais recente, dedicado a esta figura tão importante para a missão na China, encontrei uma informação que, segundo parece, escapou aos meus colegas que trataram da dicionarística histórica da língua portuguesa. Curiosamente, era um diplomata (Ramos 1988), que citou já em 1988 a mesma fonte, como eu mais tarde (desconhecia o conteúdo deste artigo até Novembro de 1995, quando recebi uma fotocópia da "Revista de Cultura de Macau" - periódico não registado nas bibliografias da Biblioteca Nacional de Lisboa. Agradeço a Dra. M. A. Espadinha Soares, Universidade de Macau, pelo envio das cópias). Eis aqui a cita:

"A dir vero un "bello vocabulario" era già fatto dal Ruggieri e dal Ricci fin dai primi anni del loro soggiorno... probabilmente negli anni 1584-1588. Già il 18 ottobre 1598 il Longobardo diceva che il Ricci aveva fatto "buona parte del calepino europeo-sinico...". Questo cimelio della sinologia, che rappresenta il primo dizionario 
europeo-cinese del mondo e a cui possiamo dare il titolo di Dizionario portoghesecinese, esiste ancora manoscritto in ARSI, Jap. Sin I, 198, dove è stato da me ritrovato e identificato nel 1934." (D'Elia 1949: 32).

Quero exprimir aqui ao Director Arquivista da Societas Jesu, J. de Cock, o meu profundo agradecimento pela rapidez e a prontidão com que respondeu ao meu pedido de tornar accessível o manuscrito deste dicionário português-chinês. Também quero tornar público o meu pesar, causado pelo facto de que nenhuma instituição portuguesa se interessa por reunir (ao menos em forma de microfilmes) todos os documentos linguísticos, testemunhos do labor que realizaram os missionários como linguistas em muitas partes do mundo. Como já antes escrevi, conheço pessoalmente muitos textos do tipo "dicionário..."; não poucos estão num estado de conservação péssimo, e vão desaparecer dentro de alguns anos.

O dicionário português-chinês encontra-se num volume-miscelânea, bem descrito por D'Elia 1949, que o descobriu em 1934. Repito aqui, o que me parece necessário para os meus leitores melhor conhecerem o texto:

“...consta di ff. 189 in carta cinese di cm. 23 x 16,5.

Prima del dizionario propriamente detto precedono vari documenti:

1) un dialogo ..., 2) Conversazioni catechetiche del Ricci..., 3) ... note di Cosmografia..., 4) I 24 periodi solari..., 5) I caratteri del cielo..., 6) Una lista di caratteri..., 7) I nomi delle province..., 8) I nomi dei 24 periodi solari.., 9) Caratteri sconnessi... Vien allora il dizionario portoghese-cinese (ff. 32-156). ...due appendici (ff. 157 - 169 e $172-186 a$ )... Dopo del dizionario vengono altre pagine..." (D'Elia 1949, 32).

Segundo o mesmo autor, o dicionário português-chinês ocupa os fólios 32-156; mas isto não corresponde completamente à realidade: há várias páginas vazias: $49 \mathrm{r}, \mathrm{v} ; 54 \mathrm{v}$; $67-71 ; 85 \mathrm{v} ; 86 ; 114 \mathrm{v} ; 135 \mathrm{r} ; 141 \mathrm{v} ; 152 \mathrm{v} ; 156 \mathrm{v} ; 159 \mathrm{v} ; 168 \mathrm{r}$.

Frequentemente as margens do manuscrito estão cortadas, o que impede de ler as palavras (sobretudo na margem superior, por exemplo fólio 107, mas tambem inferior: fólio 115).

As entradas alfabéticas distribuem-se assim:

Letra A 32r-48v; B 50r-54r; C 55r-66v; D 72r-85r; E 87r-99r; F 99v-105r; G 106v$107 \mathrm{v}$; I, J 108r-110v; L 110v-114r; M 115r-121v; N 122r-123r; O 123v-125v; P 126r-134v (e 157r); Q 135v-136r; R 137r-141r; S 142r-146v; T 147r-152r; U, V 153 r-156r; X 156r; Z 156r.

O dicionário acaba no fólio 156r com as palavras: "Laus Deo Virginique Matri. Divis Gervasio et Protasio. Amen. Jesus."

Com o fólio 158 (até 169 , e de 172,174 , e 177 até 182, e 185) começam as páginas onde se registam à maneira de suplemento mais algumas palavras (só os rectos contém as listas alfabéticas): 
A 158; B 160; C 161; D 162; E 163; F 164; G 165; I, J 166; L 167; M 168; N 172, P 174; Q 177; R 178; S 179; T 181; V 182; X 185.

As páginas do dicionário estão ordenadas em três colunas: à esquerda estão as entradas portuguesas, à direita (mas nem sempre) os caracteres chineses, e, no meio, em letras romanas, a pronunciação dos caracteres chineses. Nos fólios 32 até 34 há também uma quarta coluna: são palavras italianas, da mão de outro jesuita (Ruggieri, segundo D'Elia).

Exemplos:

$\begin{array}{llc}\text { abafar } & 0 & 0 \\ \text { abaixar } & \text { fan ti } & \text { (car. chin.) } \\ \text { abaixo } & \text { febia } & -“- \\ \text { abano } & \text { scie' zi } & -“- \\ \text { abertura } & \text { lie } & --- \\ \text { abil } & \text { zù min } & -“- \\ \text { abreviada cousa } & \text { sin sic } & -“-\end{array}$

affogarsi di calore bassarsi abasso ventaglio apertura di bell'ingegno cosa abbreviata

O último exemplo, abreviada cousa, conduz à interpretação do conteúdo desta obra lexicográfica. Na larga lista cronológica de dicionários portugueses antigos, que estou a publicar na obra "Dicionário dos dicionários portugueses", aparecem três dicionários, nos quais os adjectivos citam-se acompanhados do substantivo cousa. O dicionário de Ricci também segue esta tradição: abastada cousa, abastante cousa, aberta cousa; abominavel cousa, etc.

O último exemplo nesta série é Bento Pereira: o seu "Thesouro da Lingoa Portuguesa" (de 1647) com edições até meados do século XVIII conserva esta tradição. O seu predecessor foi A. Barbosa, de 1611, com o "Dictionarium Lusitanicolatinum...". Os dois autores não podem ter exercido nenhuma influência sobre o dicionário português-chinês, em muitos decénios mais antigo. $O$ único autor que, pela época em que redigiu o seu dicionário, pode ter sido o modelo, é J. Cardoso: da sua autoria é o primeiro dicionário português conservado, uma obra bilingue publicada pela primeira vez em 1563, onde as palavras portuguesas são traduzidas para Latim.

A comparação da obra de Ricci com a de Cardoso faz ver claramente, que era este último o modelo do missionário jesuita, ou da pessoa que transcreveu a coluna portuguesa, porque D'Elia 1949, 32 diz: “...amanuense qualunque...". Não estou de acordo com a opinião de D'Elia de se tratar duma única pessoa que escreveu as palavras portuguesas: creio ter reconhecido duas escrituras: isto vê-se muito bem no d minúsculo: nas primeiras páginas o traço alto do $\mathbf{d}$ inclina-se para a direita, mais adiante no manuscrito inclina-se para a esquerda, $\mathrm{cf}$. agradeçer, e desagradecer. E a parte inferior da cedilha inclina-se para a esquerda nos primeiros fólios, e a partir das palavras com a inicial d para a direita. Cardoso, algumas vezes, regista o adjectivo na forma masculina, sem ajuntar cousa. Isto é, por exemplo, o caso de abalado (cf. Pereira 1647: aballada cousa). Também no dicionário português-chinês está abalado, e não abalada cousa. Isto já é uma primeira informação de que Ricci não criou ex nihilo um dicionário completamente novo. Esta impressão é confirmada, se compararmos uma página dos dois dicionários, escolhida ao acaso: 


$\begin{array}{ll}\text { Cardoso } & \text { Ricci } \\ \text { Ajudar } & \text { Ajudar } \\ \text { Ajuda } & - \\ \text { Ajudador } & \text { Aiudador } \\ \text { Ajudadora } & - \\ \text { Ajudar a carga } & \text { Ayudar a carga } \\ \text { Ajuntar } & \text { Ayuntar } \\ \text { Ajuntarse } & \text { Ayuntarse } \\ \text { Ajuntada cousa } & \text { Ayuntada cousa } \\ \text { Ajuda s. cristel } & \text { Ajuda cristel }\end{array}$

Ricci (ou a pessoa que copiou Cardoso) não aceitou todas as entradas de Cardoso: faltam no nosso excerto: ajuda, ajudadora, mas segue-se totalmente a ordem nem sempre alfabética de Cardoso (v. em cima).

Tanto Woll 199o: 1725 como Teyssier 1990: 203 dizem, que a edição de Cardoso 1569 é idêntica à de 1563. Ao contrário destas opiniões, e conforme à de Telmo Verdelho (comunicação pessoal: segundo ele são 728 as novas entradas na edição de 1569), posso confirmar que há diferenças, não só por causa de novas entradas, senão também por pequenos ajuntamentos:

Cardoso 1563

abalroar, navem navi appellere.

abalisar, metor, aris, designo, as

abasta. satest, hactenus

abastecer. opulento, as, sufficio, is

abelhinha. apicula, ae

abondosa cousa. abundans, antis uber, eris, faecundus.
Cardoso 1569

abalroar. Navem navi appellere. abalroar com alguem. Congredior, eris. abalisar. Metor, aris, designo, as.

abasta. sat est, hactenus. abastarda Demissis sta pedibus abastecer. Opulento, as, sufficio, is.

abelhinha apicula, ae. dimin .

abondosa cousa. Abundans, antis, uber, eris, faecundus, $a$, um.

Se bem que Ricci não retome todas as entradas de Cardoso, temos a sorte de encontrar em Ricci 1588 algumas entradas que estão em Cardoso 1569, e não em Cardoso 1563. Um exemplo:

Abasta ...

Abastarda ...

Abasteser ...

Isso significa claramente que Ricci se baseia em Cardoso 1569 (a terceira edição de Cardoso é de 1588 , publicada então demasiado tarde para que Ricci tivesse podido conhecê-la).

Inclusive o "appendis" são 1197 entradas abaixo da letra A em Ricci; o número em Cardoso 1569 é muito mais alto: 2193. 
Há um aspecto notável relativo aos cortes que Ricci fez no material de Cardoso: faltam, por exemplo, muitas palavras de uma terminologia específica: a religiosa.

$\begin{array}{ll}\text { Cardoso 1563 } & \text { Ricci } 1588 \\ \text { Aba de vestidura } & \text { Aba de vestidura } \\ \text { Abada } & \text { (está no "appendis") } \\ \text { Abade } & - \\ \text { Abadessa } & - \\ \text { Abadinho } & - \\ \text { Abadia } & - \\ \text { Abafar } & \text { Abafar }\end{array}$

Quando, por acaso, aparecem algumas (anjo, clerigos, etc.), não há tradução chinesa.

Mas acontece também o contrário: às entradas em Cardoso: irmão, irmão inteiro, irmaã, irmaã intera ajuntou Ricci irmaã pequena, irmaã grande, irmão pequeno, irmão grande, irmaã de pai e mai (por causa da estructura da língua chinesa?).

Passemos agora à análise da língua. A grafia das palavras portuguesas em Ricci difere, por vezes, bastante da de Cardoso. Foi ele que escreveu, sendo um português de nascimento? Foi-lhe talvez ditada a lista de palavras portuguesas? Não no sabemos.

A letra a conserva-se sempre. A nasal ã varia sem regularidade nos dois dicionários:

$\begin{array}{ll}\text { Cardoso } & \text { Ricci } \\ \text { Abegam } & \text { Abegan } \\ \text { Abelhão } & \text { Abelhan } \\ \text { Acarão } & \text { Acarão } \\ \text { Açafram } & \text { Açafrão }\end{array}$

Não há emprego diferente entre o b em Cardoso e em Ricci. Quanto à letra c constatamos que como oclusiva (diante de $\mathrm{a}, \mathrm{o}, \mathrm{u}$ ) continua escrita da mesma maneira, mas antes de e, i há diferenças, inclusive aparece escrita como ç:

$\begin{array}{ll}\text { Cardoso } & \text { Ricci } \\ \text { aborrecer } & \text { aboreser } \\ \text { aborrecida cousa } & \text { aborecida cousa } \\ \text { acrecentar } & \text { acresentar } \\ \text { agradecer } & \text { agradeçer } \\ \text { antecessor } & \text { anteçeçor } \\ \text { ancinhos } & \text { amjinhos }\end{array}$

Raras vezes o digrama ch é reproduzido por outras letras: cachado (Cardoso), cayado (Ricci).

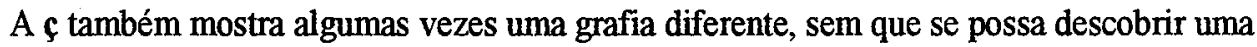
regularidade: 


$\begin{array}{ll}\text { Cardoso } & \text { Ricci } \\ \text { abençoar } & \text { abensoar } \\ \text { abraço } & \text { abraço } \\ \text { açafram } & \text { açafrão } \\ \text { beiço } & \text { bexo } \\ \text { beiçudo } & \text { beixudo } \\ \text { berço } & \text { berjo }\end{array}$

Não há mudanças na letra d. Quanto a e constatamos a mesma forma de escrevê-la nas posições tónicas. Quando átona há variações: antes escreve-se em Ricci também antis, mas só em sintagmas como aguora antis. Esta oscilação entre os grafemas e e i em sílaba átona, encontrámo-la também nos seguintes exemplos:

$\begin{array}{ll}\text { Cardoso } & \text { Ricci } \\ \text { agradecimento } & \text { agradiçimento } \\ \text { alecrim } & \text { alicrim (também alecrim) } \\ \text { beringela } & \text { biremzela } \\ \text { penhorar } & \text { pinhorar } \\ \text { penhora } & \text { pinhoro } \\ \text { pepino } & \text { pipino } \\ \text { pepinal } & \text { pipinal }\end{array}$

Não há emprego diferente do f entre Cardoso e Ricci. Algumas vezes, em Ricci, segue-se à letra g diante de $\mathrm{a}, \mathrm{o}, \mathrm{u}$ um u: alonguar, aguabar (mas gabar), aguoa etc. Também existem outros câmbios, como em biremzela $($ Ricci) $=$ berengela $($ Cardoso $)$.

A letra h aparece não só em combinações com outras consoantes (agasalhar, alcunha), mas também no verbo ir: Hir (Ricci).

Em Cardoso, para o i aparecem dois grafemas, mormente i, mas também y (aguia, ainda, ayo, ayroso). Em Ricci, estas formas escrevem-se com i diante de consoante (airoso), e com $\mathbf{y}$ diante de vocais (ayo).

Para o $\mathbf{j}$ (de uso geral em Cardoso) temos em Ricci i, j, y (aiudador, ajudar, ayuntar). O I é estável; ao contrário, a letra m mostra mudanças em Ricci: abegam em Cardoso é abegan em Ricci.

Quanto a n, em Ricci há variações como mostram alguns exemplos:

$\begin{array}{ll}\text { Cardoso } & \text { Ricci } \\ \text { abondança } & \text { abomdança } \\ \text { ancinhos } & \text { amjinhos } \\ \text { canfora } & \text { camfora } \\ \text { cantar } & \text { camtar } \\ & \text { cantar }\end{array}$


Raras vezes o o átono é reproduzido por u em Ricci: assolutamente, aferrolhar (Cardoso), asulutamente, aferulhar (Ricci).

O p continua a ser escrito da mesma maneira em Ricci e em Cardoso.

Para qu encontramos várias grafias: ao lado de esquecer, esquecida (Cardoso), esqueçer, esqueçida (Ricci), também há, para mezquinho, mezquita (Cardoso) meschino, meschita de mouros em Ricci.

O r duplo de Cardoso (aferrar) reduz-se em Ricci a um: aferar.

Para o s duplo há grafias divergentes em Ricci:

$\begin{array}{ll}\text { Cardoso } & \text { Ricci } \\ \text { atravessar } & \text { atraveçar } \\ \text { assentar } & \text { asentar } \\ \text { assinalar } & \text { asinalar } \\ \text { assi } & \text { assi } \\ \text { assi como } & \text { asi como } \\ \text { assossegar } & \text { asocegar. }\end{array}$

As letras $\mathbf{t}$ e $\mathbf{x}$ não diferem nos dois dicionários. Às palavras com u pretónica em Cardoso correspondem raramente formas com o em Ricci:

$\begin{array}{ll}\text { Cardoso } & \text { Ricci } \\ \text { acudir } & \text { acodir } \\ \text { acurtar } & \text { acortar } \\ \text { afumar } & \text { afomar. }\end{array}$

A letra u também vale como v. Em vez de chuva (Cardoso) encontramos chuiva em Ricci.

Também ocorre a troca de $\mathbf{v} \operatorname{com} \mathbf{b}$ : avaliar $($ Cardoso $)=$ abaliar (Ricci: mas avaliação) .

Também para a $\mathrm{z}$ há variantes: beleza, almazem (Cardoso) são belesa, almaxem, almagem em Ricci.

As variações gráficas que constatámos no manuscrito de Ricci (como as divergências com o seu modelo, o dicionário de Cardoso) não dão tanto na vista, se compararmos estas palavras com o material reunido por Antônio Geraldo da Cunha, no Índice do Vocabulário do Português Medieval (Rio 1986 ss.). Encontrámos já no século XV (ou antes) quase todas escritas como em Ricci. Ele (ou eles) que redigiu (redigiram) a coluna com as palavras portuguesas em Ricci, usou de uma grafia bastante conservadora. E como não escreveu da mesma maneira que Cardoso, pensámos que esta lista foi lhe ditada: as variantes, por exemplo com as quais reproduz o $\mathbf{s}$ sordo - $\mathrm{s}$, ç - não podem ser o reflexo da pronunciação. Até enganou-se a escrever em vez de Afervorarse s. darse pressa (Cardoso) Afervorrase darse preço (Ricci). 
Terminamos aqui esta breve apresentação do primeiro dicionário bilingue português (português com língua moderna), não sem deixar a ocasião de chamar a atenção para a importância desta obra.

Agradeço à Dra Maria do Rosário da Silva pela ajuda que me prestou na revisão do texto.

\section{Bibliografia}

D'Elia, Pasquale, Fonti Ricciani, Roma, 1949, Vol. II.

Messner, Dieter, Dicionário dos dicionários portugueses, Salzburg, 1994, Vol. I, II.

Messner, Dieter, "Sobre dicionários portugueses antigos: uma inventariação I", in: Lusorama 28/1995.

Ramos, João de Deus, "Os dicionários luso-sínicos, relance histórico-bibliográfico", in: Revista de Cultura Macau 16/1988, 42-47.

Teyssier, Paul, "Jerónimo Cardoso et les origines de la lexicographie portugaise", in: id. Etudes de Littérature et Linguistique, Paris, 1990.

Verdelho, Telmo, "Portugiesisch: Lexikographie", in:

Lexikon der Romanistischen Linguistik, Tübingen, 1994, Vol. VI, 2.

Woll, Dieter, "Portugiesische Lexikographie", in:

Wörterbücher, Dictionnaries, Dictionnaires, Berlin-New York, 1991, Vol. II. 


\section{PRVI DVOJEZIČNI PORTUGALSKI SLOVAR: \\ PORTUGALŠČINA - MODEREN TUJ JEZIK \\ (O starih portugalskih slovarjih. Inventarizacija II)}

Pisec tega članka je pobudnik in avtor Slovarja portugalskih slovarjev, ki je začel izhajati leta 1994. Ugotavlja, da se prvi dvojezični slovarji v Evropi, leksikalno bogastvo nekega jezika, postavljajo ob stran latinskemu besednjaku. Slovarje daljnih vzhodnih dežel pa so največkrat sestavljali misionarji, in sicer za lastno rabo ali iz svojega zanimanja.

Tak je tudi slovar patrov Ruggerija in Riccija, Diccionário português-chinês, ki je sploh prvi evropsko-kitajski slovar. Rokopis je mogoče datirati med 1584 in 1588. Patra sta bila jezuita, na Kitajsko sta prišla iz portugalske Goe v Indiji. Matteo Ricci, sicer Italijan iz Macerate, je tam dokončal študij teologije. Avtor tega prispevka je odkril rokopis v arhivih Jezuitske družbe, natančneje, lokaliziral v zvezku različnih sestavkov, ki je poznan že iz časov med obema vojnama. Ni pa bil podrobneje analiziran. Avtor tega prispevka najprej opiše način, kako je slovar narejen: portugalski besedi sledi kitajska v latinski transkripciji, potem beseda $v$ kitajskih pismenkah in še prevod $v$ italijanščino.

Avtor ugotavlja, da je bil vzorec za sestavljanje tega slovarja prvi portugalsko-latinski slovar Jeronima Cardosa (1562). Obenem pa ugotavlja nekaj pomembnih razhajanj: tako na primer, pri imenih bližnjega sorodstva, ki so v portugalsko-kitajskem slovarju mnogo bolj raznolika, bolj natančna. Morda gre za vpliv kitajske kulture in drugačne zgradbe kitajske družine, torej za sociolingvistične razloge. Avtor ugotavlja še čisto jezikovne značilnosti, še posebej odstopanja od sicer $v$ tisti dobi že ustaljene grafije, zlasti $c / c, c / s / x, q u / c h, z / s / x / g$. 